\title{
Solid-solution partitioning and thionation of diphenylarsinic acid in a flooded soil under the impact of sulfate and iron reduction
}

\author{
Meng Zhu ${ }^{\mathrm{a}, \mathrm{c}}$, Chen $\mathrm{Tu}^{\mathrm{a}}$, Xuefeng Hu ${ }^{\mathrm{a}, \mathrm{c}}$, Haibo Zhang ${ }^{\mathrm{a}, \mathrm{c}}$, Lijuan Zhang ${ }^{\mathrm{d}}$, Jing Wei ${ }^{\mathrm{a}}$, Yuan $\mathrm{Li}^{\mathrm{a}, \mathrm{c}}$, \\ Yongming Luo ${ }^{\mathrm{a}, \mathrm{b}, \mathrm{c}, *}$, Peter Christie ${ }^{\mathrm{b}}$ \\ a Key Laboratory of Coastal Environmental Processes and Ecological Remediation, Yantai Institute of Coastal Zone Research, Chinese Academy of Sciences, Yantai 264003, China \\ b Key Laboratory of Soil Environment and Pollution Remediation, Institute of Soil Science, Chinese Academy of Sciences, Nanjing 210008, China \\ c University of Chinese Academy of Sciences, Beijing 100049, China \\ d Shanghai Synchrotron Radiation Facility, Shanghai Institute of Applied Physics, Chinese Academy of Sciences, Shanghai 201800, China
}

\section{H I G H L I G H T S}

- We first investigated the solid-solution partitioning of DPAA in a flooded soil.

- We first examined the impacts of sulfate and iron reduction on DPAA partitioning.

- Elevated DPAA mobilization and thionation was observed in sulfide soil.

- DPAA mobilization associated with $\mathrm{Fe}(\mathrm{III})$ reductive dissolution was demonstrated.

- Enhanced mobilization of DPAA and sulfate reduction promoted DPAA thionation.
G R A P H I C A L A B S T R A C T

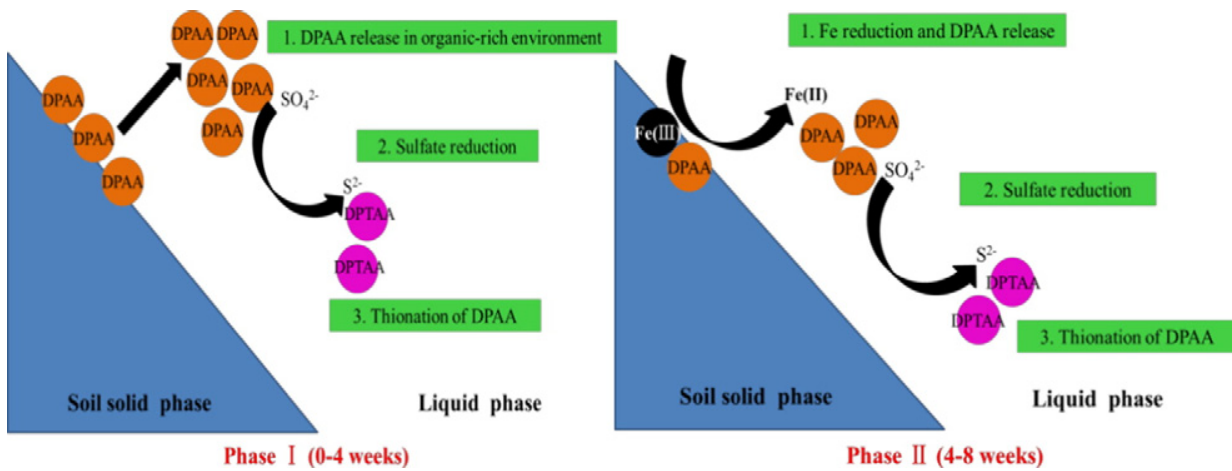

A B S T R A C T

Diphenylarsinic acid (DPAA) is a major organic arsenic (As) compound derived from abandoned chemical weapons. The solid-solution partitioning and transformation of DPAA in flooded soils are poorly understood but are of great concern. The identification of the mechanisms responsible for the mobilization and transformation of DPAA may help to develop effective remediation strategies. Here, soil and Fe mineral incubation experiments were carried out to elucidate the partitioning and transformation of DPAA in anoxic (without addition of sulfate or sodium lactate) and sulfide (with the addition of sulfate and sodium lactate) soil and to examine the impact of sulfate and $\mathrm{Fe}(\mathrm{III})$ reduction on these processes. Results show that DPAA was more effectively mobilized and thionated in sulfide soil than in anoxic soil. At the initial incubation stages ( $0-4$ weeks), $6.7-74.5 \%$ of the total DPAA in sulfide soil was mobilized likely by sorption competition with sodium lactate. At later incubation stage (4-8 weeks), DPAA was almost completely released into the solution likely due to the near-complete $\mathrm{Fe}(\mathrm{III})$ reduction. Scanning transmission X-ray microscopy (STXM) results provide further direct evidence of elevated DPAA release coupled with Fe(III) reduction in sulfide environments. The total DPAA fraction decreased significantly to $24.5 \%$ after two weeks and reached $3.4 \%$ after eight weeks in sulfide soil, whereas no obvious elimination of DPAA occurred in anoxic soil at the initial two weeks and the total DPAA fraction decreased to 10.9\% after eight weeks. This can be explained in part by the enhanced mobilization of DPAA and sulfate reduction in

\footnotetext{
* Corresponding author at: Key Laboratory of Coastal Environmental Processes and Ecological Remediation, Yantai Institute of Coastal Zone Research, Chinese Academy of Sciences, 17 Chunhui Road, Yantai 264003, China.

E-mail address: ymluo@yic.ac.cn (Y. Luo).
} 
sulfide soil compared with anoxic soil. These results suggest that under flooded soil conditions, Fe(III) and sulfate reduction significantly promote DPAA mobilization and thionation, respectively, and we suggest that it is essential to consider both sulfate and $\mathrm{Fe}(\mathrm{III})$ reduction to further our understanding of the environmental fate of DPAA.

\section{Introduction}

Chemical warfare agents containing organoarsenic compounds such as Clark I (diphenylcyanoarsine) and Clark II (diphenylchloroarsine) were widely produced both in the United States and European countries as well as in Japan during World Wars I and II (Pearson and Magee, 2002; Daus et al., 2008; Kurata, 1980). After the wars, these agents were simply abandoned by dumping at sea and landfill in several areas of northeast China (Deng and Evans, 1997), then primarily metabolized to diphenylarsinic acid (DPAA) via hydrolysis and oxidation (Haas et al., 1998; Stock and Lohs, 1997). Numerous studies have reported the presence of DPAA in contaminated soil and groundwater samples with a history of warfare (Hanaoka et al., 2005; Daus et al., 2008). Such DPAA contamination can pose a threat to water quality and human health (Ishizaki et al., 2005; Arao et al., 2009). For example, in vitro cytotoxic and genotoxic effects of DPAA have been demonstrated (Ochi et al., 2004; Kroening et al., 2009).

The environmental and health risks of contaminants in the soilwater environment are largely determined by their solid-solution partitioning and transformation. The solid-solution partitioning and transformation of inorganic arsenic (As) in the soil-water system was investigated in a number of studies (Ohtsuka et al., 2013; Yamaguchi et al., 2011; Huang et al., 2011; Al-Sid-Cheikh et al., 2015). However, there are fewer studies that have focused on these environmental processes of DPAA.

In most cases, elevated As mobilization may be related to the reductive conditions in flooded soils (Cheng et al., 2009; Langner and Inskeep, 2000; Shaheen et al., 2015). Both field and laboratory experiments to date have identified the reductive dissolution of Fe(III) (hydr)oxides driven by microbial metabolism of dissolved organic matter (DOM) to be a predominant mechanism causing inorganic As mobilization (Burton et al., 2008; Van Geen et al., 2006; Yamaguchi et al., 2011). In addition, microbially produced sulfide can efficiently reduce $\mathrm{Fe}(\mathrm{III})$ (Flynn et al., 2014) which thereby drives As release into the solution and is now considered to be an important mechanism of As mobilization in acid sulfate soils (Poulton et al., 2004; Burton et al., 2013). However, recent studies have shown that As can be either mobilized (Coker et al., 2006) or immobilized through co-precipitation (Muehe et al., 2013) or re-adsorption (Bostick and Fendorf, 2003) when secondary Fe(II)-bearing minerals are formed. Despite our understanding of the importance of $\mathrm{Fe}(\mathrm{III})$ and sulfate reduction in the partitioning of As in the soilwater environment, there is a general lack of knowledge on their influence on the partitioning of DPAA.

Enhanced As transformation in flooded soil environments has also been extensively studied and is primarily associated with sulfate reduction (Burton et al., 2013; Burton et al., 2014). Sulfide derived from microbial sulfate reduction can react directly with As to form soluble thioarsenate species or insoluble precipitates when substantial amounts of dissolved As and sulfide are present (Root et al., 2013; Stucker et al., 2014; Xu et al., 2011). Limited studies also show that DPAA can be rapidly dephenylated or methylated under flooded soil conditions (Maejima et al., 2011; Arao et al., 2009) and thionation is an important anaerobic pathway for DPAA under sulfate-reducing conditions (Guan et al., 2012; Hisatomi et al., 2013). However, the partitioning of DPAA in flooded soil was underestimated. Understanding the processes and mechanisms relating to the partitioning and transformation of DPAA in flooded soils will therefore be important to risk assessment and to the development and implementation of suitable remediation strategies.
In the present study the partitioning and transformation of DPAA in anoxic (without addition of sulfate or sodium lactate) and sulfide (with the addition of sulfate and sodium lactate) soil and the impact of sulfate and $\mathrm{Fe}(\mathrm{III})$ reduction on these processes were studied using a soil incubation experiment. The association of DPAA mobilization with the reductive dissolution of $\mathrm{Fe}(\mathrm{III})$ (hydr)oxides was further investigated by scanning transmission X-ray microscopy (STXM) using goethite as the matrix. Our study was thus designed to determine the importance of sulfate and $\mathrm{Fe}(\mathrm{III})$ reduction in the mobilization and transformation of DPAA under flooded soil conditions.

\section{Materials and methods}

\subsection{Reagents}

The DPAA (97\%) reference standard was purchased from Wako Pure Chemical Ind. Ltd. (Osaka, Japan). High-performance liquid chromatograph (HPLC) grade methanol and formic acid were obtained from Merck KGaA (Darmstadt, Germany). All other chemicals and solvents used were of analytical grade. All solutions were prepared using 18.2 $\mathrm{M} \Omega \mathrm{cm}$ ultra-pure water supplied by a Pall Cascada laboratory water system (Port Washington, New York).

\subsection{Soil}

A Haplic Phaeozem (FAO-IUSS-ISRIC, 2014) was collected from the surface horizon $(0-15 \mathrm{~cm})$ of agricultural fields in Changchun, Jilin province, northeast China. Detailed properties of the soil are: $\mathrm{pH}, 4.55$; cation exchange capacity (CEC), $30.52 \mathrm{cmol}_{\mathrm{c}} \mathrm{kg}^{-1}$; organic matter, 2.98\%; dithionite-citrate-sodium bicarbonate (DCB)-extractable $\mathrm{Fe}_{2} \mathrm{O}_{3}$, $11.5 \mathrm{~g} \mathrm{~kg}^{-1}$; DCB-extractable $\mathrm{Al}_{2} \mathrm{O}_{3}, 4.3 \mathrm{~g} \mathrm{~kg}^{-1}$; and total As, $14.1 \mathrm{mg} \mathrm{kg}^{-1}$. This sandy, arable soil consists of $10.4 \%$ clay, $58.8 \%$ sand and $30.8 \%$ silt. The soil collected was air-dried, sieved to obtain a particle size of $\leq 2 \mathrm{~mm}$ and homogenized before the incubation experiment.

\subsection{Soil incubation experiments}

Soil cultures containing $20 \mathrm{~g}$ air-dried soil and $30 \mathrm{~mL}$ ultrapure water in $100 \mathrm{~mL}$ serum bottles were prepared for anoxic and sulfide incubation. Each bottle was sealed with a butyl rubber cap and an aluminum cap equipped with a catheter introduced into the water to simulate a natural, reducing environment. Sodium lactate and sodium sulfate were added as exogenous carbon and sulfur sources at concentrations of $142 \mu \mathrm{g} \mathrm{C} \mathrm{g}{ }^{-1}$ and $426 \mu \mathrm{g} \mathrm{S} \mathrm{g}{ }^{-1}$ (dry soil basis), respectively, for sulfide incubation. The methods and conditions of preparing the sulfide slurry were modified according to Guan et al. (2012). After two weeks of pre-incubation at $25^{\circ} \mathrm{C}$ in the dark the bottles were spiked with DPAA at $30 \mathrm{mg} \mathrm{kg}^{-1}$ (dry soil basis) with a sterile syringe. All experimental vessels were shaken at $150 \mathrm{rev} \mathrm{min}^{-1}$ for $10 \mathrm{~min}$ to homogenize and then incubated at $25^{\circ} \mathrm{C}$ in the dark for up to eight weeks. Eight parallel replicates were set up.

\subsection{Sampling of soil incubation experiments}

To determine DPAA, sulfate, sulfide, Fe(II) and As species, four serum bottles were sampled destructively, $25 \mathrm{~mL}$ of the centrifuged supernatant was transferred from each of the serum bottles and stored in anaerobic pipes. Dissolved DPAA was determined first, then residue from centrifuged supernatant was freeze-dried, extracted with $\mathrm{Na}_{2} \mathrm{HPO}_{4}$ 
and DPAA concentration in the extract was measured. Some $(25 \mathrm{~mL})$ but not all of the supernatant was sampled at each sampling point to avoid removing any soil. The sum of the dissolved DPAA and DPAA in the residue was defined as total DPAA and the fraction of DPAA associated with the solid phase was calculated by the difference between the total and dissolved DPAA (total volume $30 \mathrm{~mL}$ ). Here, $\mathrm{Na}_{2} \mathrm{HPO}_{4}$ was selected as an extractant based on our previous study (Zhu et al., 2016).

The other four replicates were shaken to homogenize and $1 \mathrm{~mL}$ of slurry from each serum bottle was diluted in $9 \mathrm{~mL}$ of $1 \mathrm{~mol} \mathrm{~L}^{-1} \mathrm{HCl}$ to dissolve all minerals and to prevent $\mathrm{Fe}$ (II) oxidation until measurement after $24 \mathrm{~h}$ (Lovley and Phillips, 1986). The supernatant was used for quantification of $\mathrm{HCl}$-extractable $\mathrm{Fe}(\mathrm{II})$ and $\mathrm{HCl}$-extractable total $\mathrm{Fe}$ according to Kappler et al. (2004). 2 mL of slurry from each serum bottle was centrifuged and the residue was freeze-dried for the determination of total sulfur in the solid phase. The As species were analyzed by collecting the supernatants and soil extracts after four weeks of incubation. To prevent further reaction/oxidation, (1) all sampling was done under $\mathrm{N}_{2}$ atmosphere and $\mathrm{N}_{2}$ was introduced into all bottles containing supernatant or reaction solution; (2) all supernatants were stored at $4{ }^{\circ}$ $\mathrm{C}$ freezer immediately after removal from the $\mathrm{N}_{2}$ atmosphere; (3) the residues were stored at $-20{ }^{\circ} \mathrm{C}$ freezer immediately after removal from the $\mathrm{N}_{2}$ atmosphere and then freeze-dried for 2 days; (4) dissolved sulfide and $\mathrm{Fe}$ (II) were measured immediately after sample preparation; and (5) dissolved DPAA, sulfate and As species were analyzed that day.

\subsection{Analytical methods}

Different organic arsenic species were detected and quantified by a method described in our previous study (Zhu et al., 2016) using high performance liquid chromatography (HPLC) with a Sunfire $C_{18} 3.5 \mu \mathrm{m}$, $2.1 \mathrm{~mm} \times 150 \mathrm{~mm}$ column (Waters, Milford, USA) and a Sunfire $C_{18}$ $3.5 \mu \mathrm{m}, 2.1 \mathrm{~mm} \times 10 \mathrm{~mm}$ guard column (Waters, Milford, USA). The mobile phase was $\mathrm{H}_{2} \mathrm{O}$ containing $0.1 \%$ formic acid and $\mathrm{CH}_{3} \mathrm{OH}$ containing $0.1 \%$ formic acid. HPLC coupled to tandem mass spectrometry (TSQ Quantum Access MAX, Thermo Fisher Scientific, San Jose, CA) with an electrospray interface operating in the positive ion mode was used for organic arsenic detection. The minimum detection limit of DPAA was $0.01 \mu \mathrm{g} \mathrm{L}^{-1}$. Dissolved inorganic As was determined using atomic fluorescence spectrometry (AFS-930, Beijing Jitian Instrument Co., China). Dissolved $\mathrm{Fe}(\mathrm{II}), \mathrm{HCl}$-extractable $\mathrm{Fe}(\mathrm{II})$ and $\mathrm{HCl}$-extractable total $\mathrm{Fe}$ were determined spectrophotometrically using the ferrozine assay (Lovley and Phillips, 1986). Soluble sulfate was measured by barium sulfate turbidimetry (Lu, 2000). Dissolved sulfide was determined spectrophotometrically as a colloidal solution of copper sulfide according to Cord-Ruwisch (1985) immediately following sample preparation. Total sulfur in the soil solid-phase was determined on a CHNS analyzer (Vario Micro cube, Elementar, Hanau, Germany). Eh and pH, respectively, were measured with a Pt and a glass electrode.

\subsection{Fe mineral incubation experiment}

Goethite was synthesized according to Schwertmann and Cornell (2000) and verified by X-ray diffraction (XRD). Sulfate-reducing bacterial (SRB) slurry was prepared by inoculating $100 \mu \mathrm{L}$ of sulfide soil slurry into $30 \mathrm{~mL}$ of sterilized enrichment medium $\left(0.5 \mathrm{~g} \mathrm{~L}^{-1} \mathrm{~K}_{2} \mathrm{HPO}_{4}\right.$; $3.0 \mathrm{~g} \mathrm{~L}^{-1} \mathrm{Na}_{2} \mathrm{SO}_{4} ; 1.0 \mathrm{~g} \mathrm{~L}^{-1} \mathrm{NH}_{4} \mathrm{Cl} ; 0.4 \mathrm{~g} \mathrm{~L}^{-1} \mathrm{MgCl} \cdot 6 \mathrm{H}_{2} \mathrm{O} ; 0.05 \mathrm{~g} \mathrm{~L}^{-1}$ $\mathrm{CaCl}_{2} \cdot 6 \mathrm{H}_{2} \mathrm{O} ; 0.05 \mathrm{~g} \mathrm{~L}^{-1} \mathrm{FeSO}_{4} ; 0.1 \mathrm{~g} \mathrm{~L}^{-1}$ vitamin C; $0.1 \mathrm{~g} \mathrm{~L}^{-1}$ sodium thioglycolate; $35.6 \mathrm{mmol} \mathrm{L}^{-1}$ sodium lactate; $1 \mathrm{~g} \mathrm{~L}^{-1}$ yeast extracts; $\mathrm{pH}$ 7.50) and incubated at $25{ }^{\circ} \mathrm{C}$ in the dark. After three rounds of subculturing, $100 \mu \mathrm{L}$ of slurry was transferred to a $100 \mathrm{~mL}$ serum bottle, the sterilized enrichment medium containing goethite $\left(10 \mathrm{~g} \mathrm{~L}^{-1}\right)$ instead of $\mathrm{FeSO}_{4}$ was added to give a total liquid volume of $100 \mathrm{~mL}$, and the bottle was spiked with DPAA at $10 \mathrm{mg} \mathrm{kg}^{-1}$. A background control (in the absence of bacteria, but using the same solution composition as for goethite incubated with SRB slurry) was also prepared.

\subsection{STXM analysis}

Approximately $1 \mu \mathrm{L}$ of suspension sample containing goethite, bacteria and DPAA was taken after 10 days of incubation. The sample was sandwiched between two 100 -nm-thick $\mathrm{Si}_{3} \mathrm{~N}_{4}$ windows. The mapping of the spatial distribution of As and Fe on goethite was performed using scanning transmission X-ray microscopy (STXM) at the soft Xray beamline (BL08U1A) at the Shanghai Synchrotron Radiation Facility (SSRF), China. DPAA, $\mathrm{FeSO}_{4}$ and $\mathrm{Fe}_{2}\left(\mathrm{SO}_{4}\right)_{3}$ were chosen as the reference compounds for X-ray absorption near edge structure (XANES) analysis.

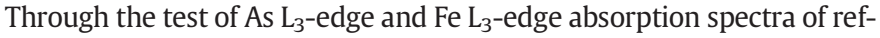
erence compounds, two energy values (on the absorption edge $\mathrm{E}_{1}$ and away from the absorption edge $E_{2}$ ) were obtained. 2D distributions of As and Fe in the selected areas were obtained by analyzing the two images via a dual energy contrast imaging method using IDL 7.06 (Exelis Visual Information Solution, Inc. Boulder, CO) software (Xia et al., 2013; Zhang et al., 2010). The maximum and minimum surface densities of the element were obtained according to the "maxquantitative" and "minquantitative" values given by the IDL 7.06 software. The background control was also subjected to STXM analysis.

\section{Results}

\subsection{Solid-solution partitioning of DPAA in anoxic and sulfide soil}

Figs $1 \mathrm{~A}$ and $\mathrm{B}$ show changes in the fractions of dissolved and solidphase associated DPAA in anoxic and sulfide soil, respectively. The dissolved DPAA fraction in sulfide soil $(74.5 \%)$ was significantly higher than that in anoxic soil (44.0\%) at time zero, primarily due to sodium lactate addition according to the adsorption results (Fig. S1). During the initial two weeks of incubation the dissolved DPAA percentage decreased rapidly from 74.5 to $19.5 \%$ in sulfide soil within two weeks of incubation. Concurrently, a slower decrease in dissolved DPAA was observed in anoxic soil. This decrease can be attributed to DPAA adsorption because (1) no discernible change was observed in total DPAA during the two-week period and (2) the initial dissolved DPAA was determined $10 \mathrm{~min}$ after spiking while the adsorption equilibrium was reached at least $72 \mathrm{~h}$ later according to our previous study (Li, 2011). During 2-4 weeks of incubation the dissolved DPAA fraction declined steadily to $0.7 \%$ in anoxic soil and almost all the DPAA was associated with the solid phase at later incubation stages (4-8 weeks) (Fig. 1A). However, a slight increase in the dissolved DPAA fraction was observed in sulfide soil (3.4-6.8\%) compared with anoxic soil (0.3-0.7\%) and DPAA was almost completely released into the solution after four weeks of incubation (Fig. 1A and B). These results suggest that DPAA was substantially mobilized in sulfide soil at later incubation stages (4-8 weeks).

\subsection{Transformation of DPAA in anoxic and sulfide soil}

Changes in the total DPAA fractions in anoxic and sulfide soil are presented in Figs $1 \mathrm{~A}$ and $\mathrm{B}$, respectively. There was no obvious elimination of total DPAA in anoxic soil during the initial two weeks but a rapid decrease in total DPAA (52.9\%) was observed in sulfide soil during this incubation stage. The total DPAA fractions finally decreased to $10.9 \%$ and $3.4 \%$ in anoxic and sulfide soil, respectively. Overall, a rapid and final enhanced DPAA elimination occurred in sulfide soil compared with anoxic soil.

A dramatic decrease in total and dissolved DPAA was observed in anoxic soil during 2-4 weeks of incubation (Fig. 1A). A rapid and then slower decrease in total DPAA was observed in sulfide soil within four weeks of incubation and similar trends were obtained for dissolved DPAA (Fig. 1B). This suggests that dissolved DPAA is more easily eliminated (reacted or degraded) than soil-phase associated DPAA. In addition, total DPAA slowly decreased in anoxic soil at the end of the incubation (4-8 weeks) with no discernible change in the dissolved 

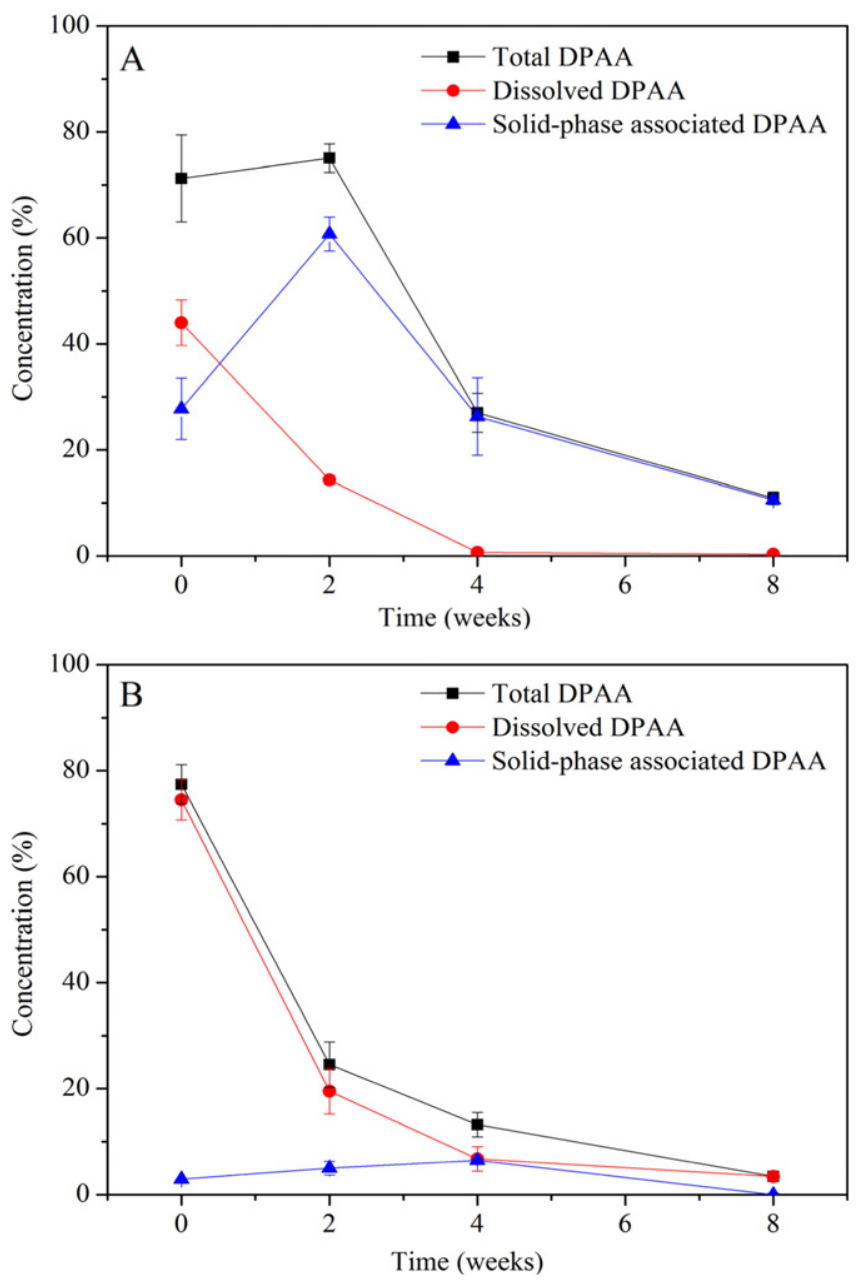

Fig. 1. Changes in the fractions of total DPAA, dissolved DPAA and solid-phase associated DPAA in anoxic (without addition of sulfate or sodium lactate) (A) and sulfide (with the addition of sulfate and sodium lactate) (B) soil. Each point and bar corresponds to the mean \pm SD $(n=4)$. The total DPAA fraction was calculated as the ratio of the mass of total DPAA obtained at each sampling point to the mass of total DPAA added ( $0.6 \mathrm{mg})$. The dissolved and solid-phase associated DPAA fractions were calculated as the ratio of the mass of dissolved and solid-phase associated DPAA obtained at each sampling point to the mass of total DPAA added, respectively.

DPAA fraction (Fig. 1A). It can be inferred that solid-phase associated DPAA can be further eliminated when dissolved DPAA is depleted.

The metabolites in the extracts and suspensions of anoxic and sulfide soil were also examined and the results are shown in Fig. S2. A novel peak at $t_{\mathrm{R}}=22.56-22.73$ min occurred in all samples (Fig. S2A, $\mathrm{B}, \mathrm{C}$ and $\mathrm{D}$ ) and in solution obtained by chemical reaction of DPAA with hydrogen sulfide (Fig. S2E). The mass spectrum for this peak showed a major molecular $[\mathrm{M}+\mathrm{H}]^{+}$ion peak at $m / z 279.1$ and fragment ions at $m / z$ 260.9, 182.9, 152.0 and 107.0 (Fig. S2F), suggesting that diphenylthioarsinic acid (DPTAA) was a major metabolite of DPAA in both anoxic and sulfide soil.

\subsection{Sulfate reduction in anoxic and sulfide soil}

Figs $2 \mathrm{~A}$ and $\mathrm{B}$ show the concentrations of dissolved sulfate and sulfide in anoxic and sulfide soil throughout the period of incubation. Sulfate concentrations in sulfide soil decreased rapidly over time during the initial two weeks (Fig. 2A) and the depletion of sulfate was coupled with the evolution of dissolved sulfide (Fig. 2B). However, despite the significant decrease in concentrations of dissolved sulfate during 0 4 weeks incubation (Fig. 1B), the concentrations of dissolved sulfide remained relatively low (4.8-7.2 $\left.\mathrm{mg} \mathrm{L}^{-1}\right)$ during the whole incubation stage. It has been observed that sulfide soil darkened quickly after one week of incubation and reducing conditions were quickly induced as the Eh values decreased to $-134 \mathrm{mV}$ after two weeks (Fig. S3). The calculated ion products of $\mathrm{Fe}$ (II) (Fig. $3 \mathrm{~A}$ ) and sulfide were $4.15 \times 10^{-8}$, $9.49 \times 10^{-9}, 2.57 \times 10^{-8}$ and $1.97 \times 10^{-8}\left(\mathrm{~mol} \mathrm{~L}^{-1}\right)^{2}$ at $0,2,4$ and 8 weeks, respectively. All ion products exceeded the solubility product constant $\left(K_{\mathrm{sp}}\right)$ of FeS $\left(6.25 \times 10^{-18}\right)$ and hence the formation of FeS precipitate. Black precipitates that formed in sulfide soil during the incubation period were likely due to the formation of FeS and also other metal (e.g. Mn) sulfides (data not shown). A significant increase in solid-phase associated sulfur further implies the formation of metal sulfide precipitates in sulfide soil (Fig. S4) and this may explain why the concentrations of dissolved sulfide remained relatively low throughout the entire incubation period (Fig. 2B).

In contrast to sulfide soil, anoxic soil showed no obvious dark color and the Eh value $(250 \mathrm{mV})$ after two weeks of incubation was significantly higher than that in sulfide soil (Fig. S3). There is a probable that little sulfate reduction could occur in anoxic soil according to Figs $2 \mathrm{~A}$ and $\mathrm{B}$. The calculated ion products of $\mathrm{Fe}$ (II) (Fig. $3 \mathrm{~A}$ ) and sulfide were $0,0,1.54 \times 10^{-9}$ and $3.82 \times 10^{-10}\left(\mathrm{~mol} \mathrm{~L}^{-1}\right)^{2}$ at $0,2,4$ and 8 weeks, respectively. Moreover, a slight increase in solid-phase associated sulfur was observed after four weeks incubation (Fig. S4). These results indicate that FeS might form in anoxic soil at later incubation stage (48 weeks). Based on these results it can be inferred that both endogenous and exogenous sulfate were partly reduced to sulfide under flooded soil conditions in the current study.
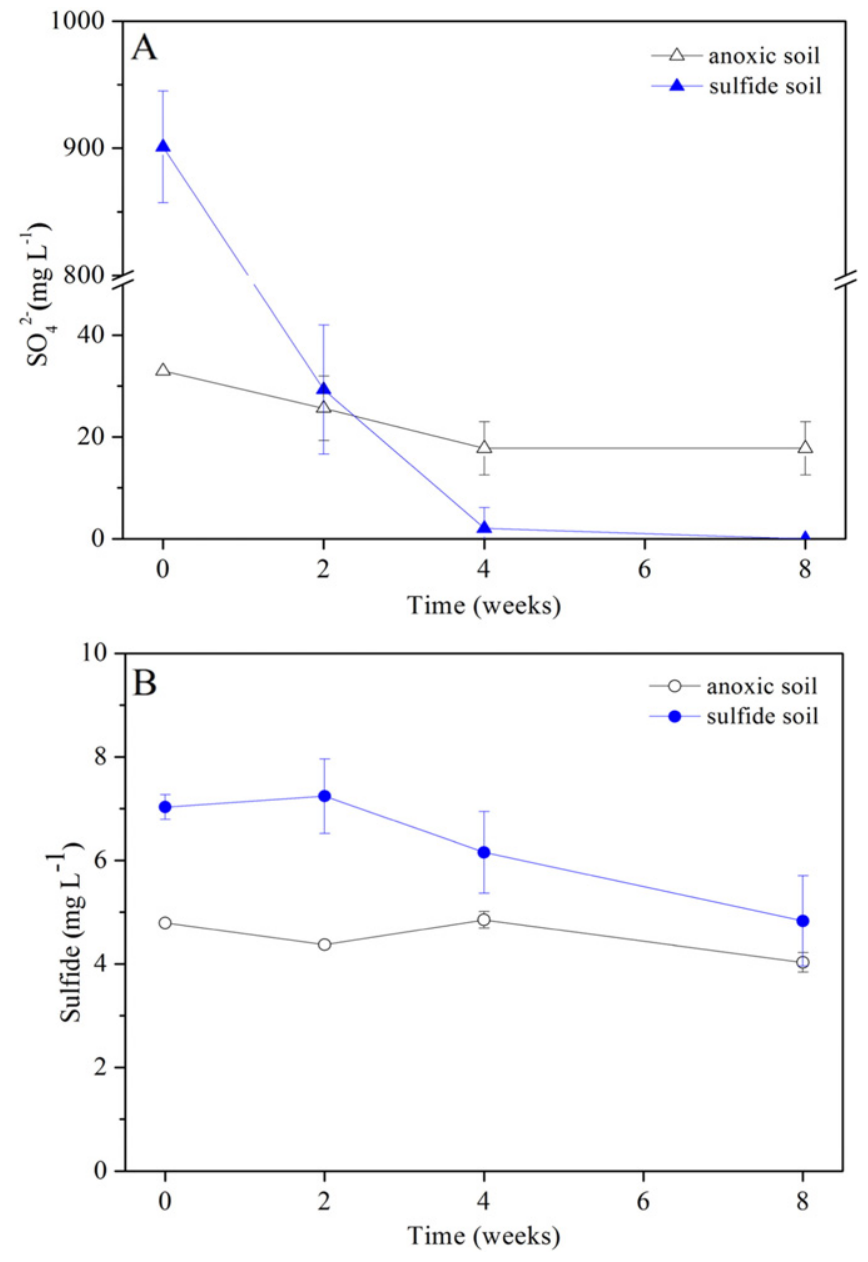

Fig. 2. Changes in the concentrations of dissolved sulfate (A) and sulfide (B) in anoxic (without addition of sulfate or sodium lactate) and sulfide (with the addition of sulfate and sodium lactate) soil. Each point and bar corresponds to the mean $\pm \operatorname{SD}(n=4)$. 

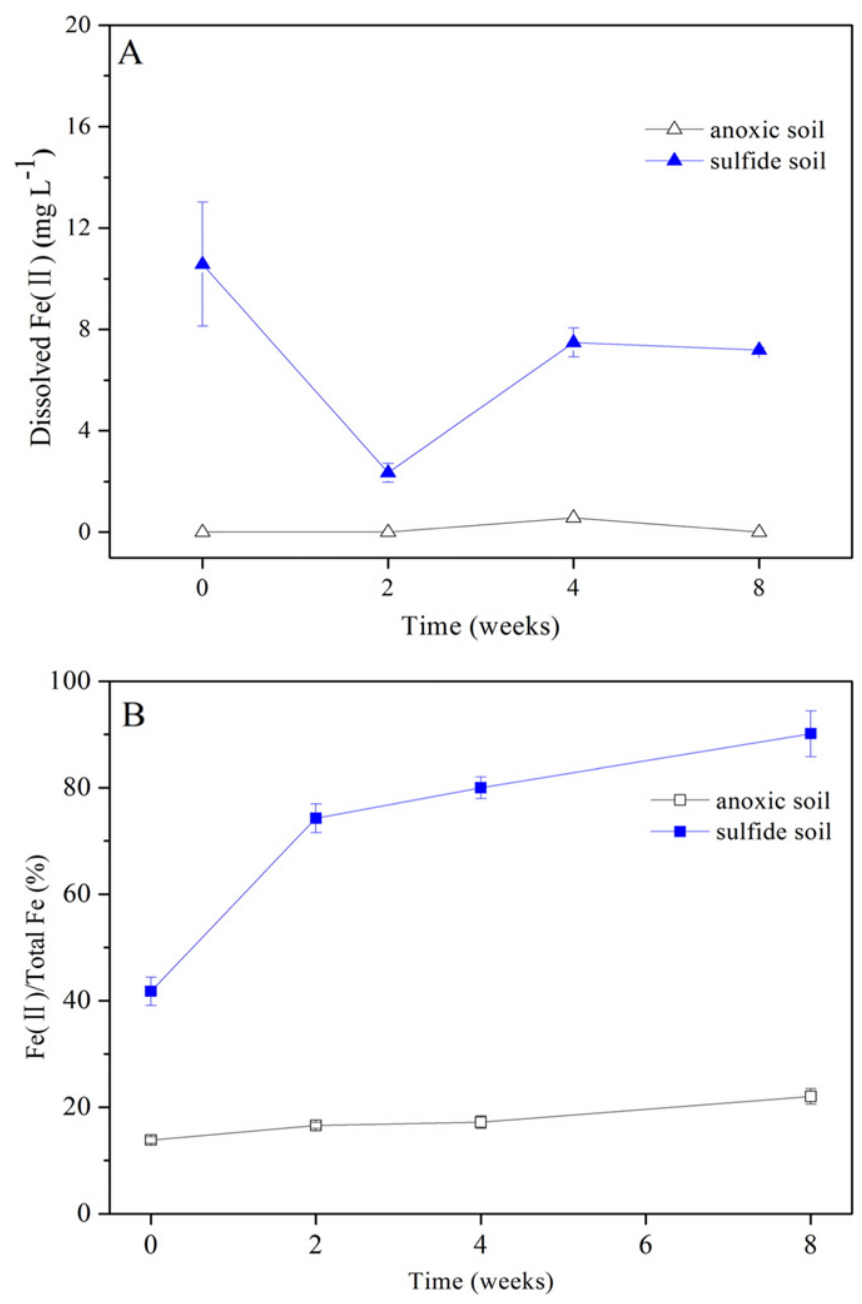

Fig. 3. Changes in the concentration of dissolved $\mathrm{Fe}(\mathrm{II})$ (A) and the fraction of $\mathrm{HCl}-$ extractable $\mathrm{Fe}$ (II) to $\mathrm{HCl}$-extractable total $\mathrm{Fe}(\mathrm{B})$ in anoxic (without addition of sulfate or sodium lactate) and sulfide (with the addition of sulfate and sodium lactate) soil. Each point and bar corresponds to the mean $\pm \operatorname{SD}(n=4)$.

\section{4. $\mathrm{Fe}(\mathrm{III})$ reduction in anoxic and sulfide soil}

The reductive dissolution of Fe(III) (hydr)oxides can be monitored by following changes in dissolved $\mathrm{Fe}$ (II) (Fig. 3A) and HCl-extractable $\mathrm{Fe}(\mathrm{II})$ (Fig. 3B). It was found that Fe(III) (hydr)oxides were subjected to biotically-generated reducing conditions and underwent rapid reductive dissolution in sulfide soil after the initial two weeks. At the end of the incubation period, $>90 \%$ of $\mathrm{Fe}$ (III) (hydr)oxides were reduced in sulfide soil. Large quantities of Fe(II) were produced and sequestered in the solid phase with the development of reducing conditions but little dissolved in the solution in sulfide soil (Fig. 3A). This corresponds well with the formation of FeS precipitates. In contrast to sulfide soil, only a slight reduction of $\mathrm{Fe}(\mathrm{III})$ (hydr)oxides was observed in anoxic soil according to Figs $3 \mathrm{~A}$ and $\mathrm{B}$.

\subsection{STXM analysis of As and Fe on goethite surfaces}

The As $\mathrm{L}_{3}$-edge spectrum of DPAA was first measured and showed an absorption peak at $1328.5 \mathrm{eV}$ (Fig. 4A). The $\mathrm{Fe}_{3}$-edge spectra of $\mathrm{FeSO}_{4}$ and $\mathrm{Fe}_{2}\left(\mathrm{SO}_{4}\right)_{3}$ are shown in Fig. 4B. The main difference between $\mathrm{Fe}(\mathrm{II})$ and $\mathrm{Fe}(\mathrm{III})$ are the relative intensities of the peaks at 708.6 and $710.0 \mathrm{eV}$. STXM images obtained by dual-energy contrast analysis of As and Fe distribution on goethite, as shown in Fig. 4C, D, E and F, where Fig. 4C and $\mathrm{E}$ refer to goethite incubated without SRB slurry and taken as a control. According to the color bar of each image the surface densities of As spread on goethite incubated with and without SRB slurry were $0.59 \times 10^{-5}-3.10 \times 10^{-5}$ and $0.61 \times 10^{-5}-5.34 \times 10^{-5} \mathrm{~g}\left(\mathrm{~cm}^{2}\right)^{-1}$, respectively. It appears that the surface density of As in culture with SRB slurry decreased dramatically in comparison with the control culture. The lower surface density of As at least indicates a decrease in the content of solid-phase associated DPAA in culture with SRB slurry, which was further demonstrated by HPLC-MS/MS analysis (Table S1). Since $>93.3 \%$ of the total DPAA was still presented in culture with SRB slurry after 10 days of incubation, the significant decrease in the content of solid-phase associated DPAA indicates DPAA mobilization to a large extent.

The sub-micro distribution of Fe in a single platelet of goethite was also determined using STXM. STXM images taken at $708.6 \mathrm{eV}\left(\mathrm{E}_{1}=\right.$ $708.6 \mathrm{eV}, \mathrm{E}_{2}=706.0 \mathrm{eV}$ ) indicate $\mathrm{Fe}(\mathrm{II})$-rich regions to a large extent according to Hunter et al. (2008). The surface densities of Fe spread on goethite incubated with and without SRB slurry were close to $0.45 \times 10^{-5}-5.00 \times 10^{-5}$ and $0.47 \times 10^{-5}-2.02 \times 10^{-5} \mathrm{~g}\left(\mathrm{~cm}^{2}\right)^{-1}$, respectively, suggesting that $\mathrm{Fe}(\mathrm{II})$ was more abundant in the culture with SRB slurry. XRD analysis shows that goethite incubated with SRB slurry was partially transformed to vivianite $\left(\mathrm{Fe}\left(\mathrm{PO}_{4}\right) \cdot 8 \mathrm{H}_{2} \mathrm{O}\right)$ after 10 days of incubation (data not shown). It is well-known that vivianite is formed during microbial reduction of $\mathrm{Fe}(\mathrm{III})$ (hydr)oxides (Azama and Finneranb, 2014). These results suggest the enhanced Fe(III) reductive dissolution in culture with SRB slurry compared with that without SRB slurry.

\section{Discussion}

\subsection{Impact of $\mathrm{Fe}(\mathrm{III})$ reduction on DPAA partitioning}

At the initial incubation stages (0-4 weeks) DPAA in sulfide soil was mobilized primarily due to sodium lactate addition since sodium lactate may mobilize DPAA by covering adsorption sites on Fe(III) (hydr)oxides and/or competitive adsorption (Polizzotto et al., 2006; Sharma et al., 2010; Sharma et al., 2011). At later incubation stages (4-8 weeks) DPAA was almost completely released into the solution in sulfide soil while associated with the solid-phase in anoxic soil (Fig.1A and B), which is likely due to the near-complete reductive dissolution of $\mathrm{Fe}$ (III) (hydr)oxides in sulfide soil. Despite the fact that Fe(III) reduction proceeded throughout the incubation period (Fig. 3A and B), appreciably large amounts of dissolved DPAA in sulfide soil at early stages ( 0 4 weeks) may weaken the role of Fe(III) reduction in promoting DPAA mobilization. However, it has been proposed that As will be mobilized mainly by $\mathrm{Fe}(\mathrm{III})$ reduction in carbon-limited environments where organic matter does not play a role (Masscheleyn et al., 1991).

Based on the hypothesis that DPAA mobilization in sulfide soil at later incubation stage (4-8 weeks) resulted from $\mathrm{Fe}$ (III) reduction, we performed an Fe mineral incubation experiment as described above. Sodium lactate was also added to the background control culture to counteract the impact of sodium lactate on DPAA mobilization. STXM results indicate that elevated DPAA release coupled with the reductive dissolution of Fe(III) (hydr)oxides did occur in sulfide environments (Fig. 4C, D, $\mathrm{E}$ and $\mathrm{F}$ ). However, it is still unclear whether DPAA mobilization in sulfide soil at later incubation stages (4-8 weeks) resulted directly from $\mathrm{Fe}(\mathrm{III})$ reduction.

Some possible factors that have to be considered include (1) $\mathrm{pH}$ and (2) competitive adsorption between DPAA and DPTAA. Results show that the $\mathrm{pH}$ values (6.51-6.81) of sulfide soil remained relatively constant at later incubation stages (4-8 weeks) (Fig. S3), indicating that $\mathrm{pH}$ is not a key factor in the control of the DPAA mobilization. We also discount the competitive adsorption of DPTAA as a mechanism for DPAA mobilization because when a substantial amount of DPTAA was present, DPAA in anoxic soil was sequestered mainly to the solid phase after four weeks of incubation (Fig. 1A, Table 1). These results strongly suggest that DPAA mobilization occurred in sulfide soil (the 

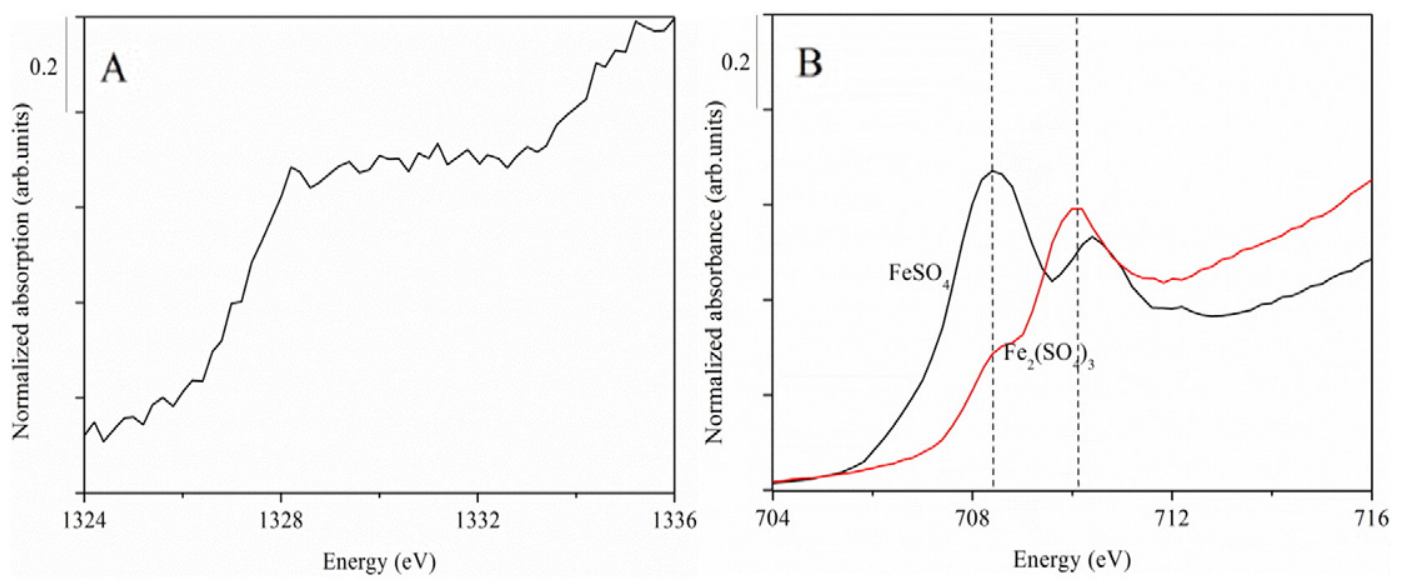

4.68

C

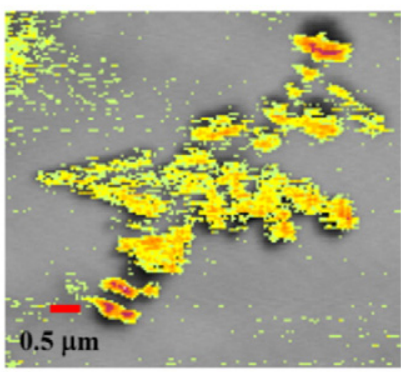

E

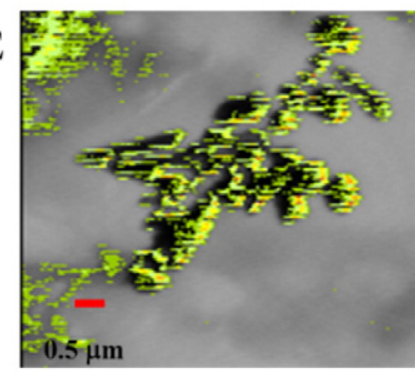

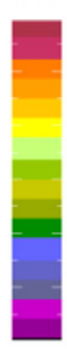

0.61
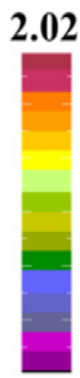

0.47

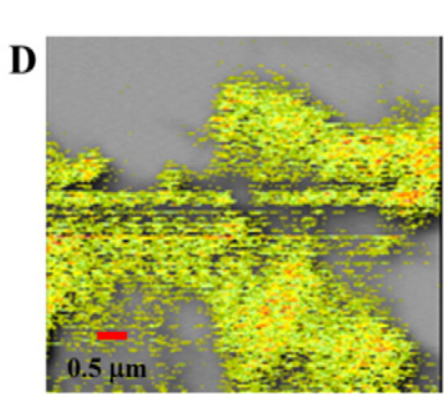

2.98

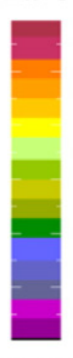

0.48

5.00

F
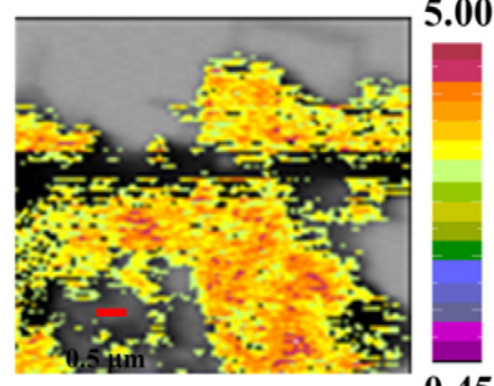

0.45

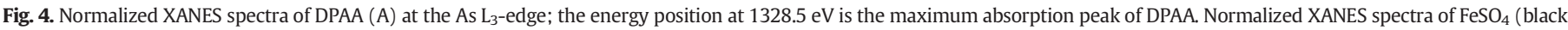

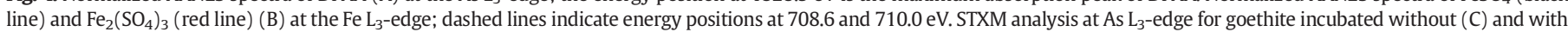

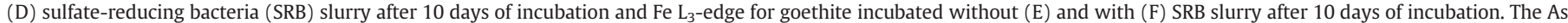

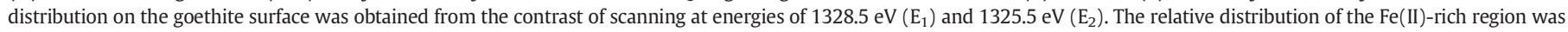

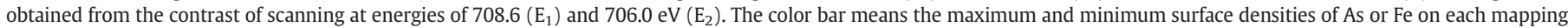

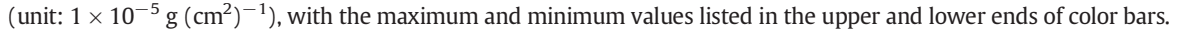

dissolved DPAA fraction was 3.4-6.8\%) compared with anoxic soil (the dissolved DPAA fraction was $0.3-0.7 \%$ ) at later incubation stages (48 weeks) (Fig. $1 \mathrm{~A}$ and $\mathrm{B}$ ) could be attributed to the near-complete reductive dissolution of Fe(III) (hydr)oxides (Pedersen et al., 2006; Van Geen et al., 2004).

In addition to the reductive dissolution of Fe(III) (hydr)oxides, the subsequent formation of secondary Fe minerals may also significantly influence the solid-solution partitioning of As (Hansel et al., 2003). The relatively low fractions of solid-phase associated DPAA $(<10 \%)$ (Fig. 1B) in sulfide soil throughout the incubation tends to indicate that no obvious adsorption of DPAA onto secondary Fe(II)-bearing minerals occurred. Although As may sorb to FeS and other Fe sulfides by surface precipitation (Bostick and Fendorf, 2003), DPAA adsorption onto FeS and pyrite was reduced by sodium lactate to a certain extent (Fig. S5). Moreover, the negligible DPAA adsorption onto secondary Fe minerals may be explained if dissolved As (data not shown) and DPTAA
(Table 1) inhibit DPAA adsorption either through occupying the adsorption sites or co-precipitation of As with secondary Fe minerals, or through both reactions.

Table 1

The fractions of dissolved and solid-phase associated DPTAA ${ }^{\mathrm{a}}$ in anoxic (without addition of sulfate or sodium lactate) and sulfide (with the addition of sulfate and sodium lactate) soil at four weeks of incubation time.

\begin{tabular}{lll}
\hline Treatment & Anoxic soil & Sulfide soil \\
\hline Dissolved DPTAA (\%) & 20.1 & 15.8 \\
Solid-phase associated DPTAA (\%) & 79.9 & 84.2
\end{tabular}

\footnotetext{
a The concentrations of dissolved and solid-phase associated DPTAA were quantitatively calculated according to the standard curve of DPAA due to the lack of DPTAA standard. All values are the average of four replicates.
} 


\subsection{Impact of sulfate and $\mathrm{Fe}(\mathrm{III})$ reduction on DPAA thionation}

Our results show a rapid and final enhanced DPAA thionation in sulfide soil compared with anoxic soil (Fig. 1A and B, Table S2) and this may be attributed to SRB activity as first reported by Guan et al. (2012). DPTAA was a major metabolite of DPAA in sulfide soil and this is consistent with previous results reported by Hisatomi et al. (2013). In the present study some soluble sulfide in anoxic soil also transformed DPAA to DPTAA despite the lack of exogenous sulfate addition. This is not entirely unexpected and is likely due to the rapid reaction of DPAA with sulfide generated by the reduction of endogenous sulfate. It is also notable that $2.44 \mathrm{mg} \mathrm{L}^{-1}$ sulfide is sufficient to completely transform all the DPAA added $(0.6 \mathrm{mg})$ in each soil incubation culture to DPTAA under the present experimental conditions. Thus, we propose that DPAA can be slowly thionated in soil-water or sediment-water systems under conditions in which sulfate reduction occurs to only a negligible or small degree. In contrast, a more rapid and final enhanced DPAA thionation may be obtained in the presence of more substantial sulfate reduction (Table S2).

The formation of DPTAA can be detected either in chemical solution containing sulfide but without SRB (Fig. S2E) or in sulfate-reduced soil cultures (Fig. S2C and D), suggesting that the formation of DPTAA is likely due to the direct chemical reaction between DPAA and sulfide. Previous studies also demonstrated that thioarsenate species can be formed directly in solution, for example, via the reactions between pheylarsonic acid (PAA) and sulfide (Hempel et al., 2009), as well as arsenite and sulfide (Wallschläger and Stadey, 2007). We therefore propose that the concentrations of dissolved sulfide and DPAA may strongly influence DPAA thionation irrespective of whether DPAA thionation proceeds exclusively in solution or is also involved in the solid phase. Actually, our result suggests that DPAA thionation proceeds predominantly in solution in sulfide soil and involves also direct thionation of adsorbed DPAA in anoxic soil (see Section 3.2). It can be seen that DPTAA associated mainly with the solid phase in both anoxic and sulfide soil at four weeks incubation time (Table 1), which corresponds well with the direct thionation of adsorbed DPAA in anoxic soil and possibly indicates the readsorption of DPTAA to the solid phase under sulfate-reducing conditions. Based on these results, we suggest that the enhanced DPAA mobilization and sulfate reduction contribute significantly to the rapid and final increased DPAA thionation in sulfide soil compared with that in anoxic soil.

Bostick et al. (2004) and Wilkin and Ford (2006) concluded from their studies that microbially produced sulfide can react with $\mathrm{Fe}(\mathrm{II})$ or $\mathrm{Fe}(\mathrm{III})$, or form FeAsS-like precipitates which sequence As. Of these, the formation of thioarsenate species, in particular, is reduced by reactive $\mathrm{Fe}(\mathrm{II})$ or $\mathrm{Fe}(\mathrm{III})$ through sulfide oxidation, complexation, or precipitation (Fakih et al., 2009; Kocar et al., 2010). Despite the fact that the dissolved $\mathrm{Fe}(\mathrm{II})$ can easily form a precipitate with sulfide according to the low $K_{\mathrm{sp}}$ values, the near-complete reduction of Fe(III) (>80\%) in sulfide soil after four weeks (Fig. 3B) did not inhibit DPAA thionation since a significant amount of DPTAA was found thereafter (Fig. 1B, Table 1). This can be explained in part by the rapid reaction between DPAA and sulfide.

\section{Conclusions}

DPAA underwent significant mobilization and enhanced thionation in sulfide soil compared with anoxic soil. Exogenous sodium lactate promoted DPAA mobilization at the initial stages of incubation (04 weeks), possibly by covering adsorption sites of Fe minerals and/or competitive adsorption. The increased DPAA mobilization at later incubation stages (4-8 weeks) was primarily associated with the reductive dissolution of $\mathrm{Fe}$ (III) (hydr)oxides. The fact that DPAA thionation was more rapid and finally increased in sulfide soil compared with that in anoxic soil may have resulted from enhanced DPAA mobilization and sulfate reduction. The results highlight the key role of sulfate and
$\mathrm{Fe}(\mathrm{III})$ reduction in the partitioning and thionation of DPAA in sulfide environments and the need to consider both sulfate and Fe(III) reduction in predicting the environmental fate of DPAA. Although adding exogenous carbon and sulfate sources has been recognized as a biostimulation method to decrease DPAA concentrations in flooded soils, the significant DPAA mobilization under sulfate-reducing conditions is underappreciated. The potential risks associated with DPAA mobilization in flooded soils should be considered before the application of this biostimulation method.

\section{Acknowledgements}

This work was supported by the National Natural Science Foundation of China (Projects 41571310, 41230858 and 41201313). The authors would like to thank Dr. Ying Liu for HPLC-MS/MS analysis and Prof. Alice Newton for the English language revision.

\section{Appendix A. Supplementary data}

Supplementary data to this article can be found online at http://dx. doi.org/10.1016/j.scitotenv.2016.07.001.

\section{References}

Al-Sid-Cheikh, M., Pédrot, M., Dia, A., Guenet, H., Vantelon, D., Davranche, M., Gruau, G., Delhaye, T., 2015. Interactions between natural organic matter, sulfur, arsenic and iron oxides in re-oxidation compounds within riparian wetlands: NanoSIMS and Xray adsorption spectroscopy evidences. Sci. Total Environ. 515, 118-128.

Arao, T., Maejima, Y., Baba, K., 2009. Uptake of aromatic arsenicals from soil contaminated with diphenylarsinic acid by rice. Environ. Sci. Technol. 43, 1097-1101.

Azama, H.M., Finneranb, K.T., 2014. Fe(III) reduction-mediated phosphate removal as vivianite $\left(\mathrm{Fe}_{3}\left(\mathrm{PO}_{4}\right)_{2} \cdot 8 \mathrm{H}_{2} \mathrm{O}\right)$ in septic system wastewater. Chemosphere $97,1-9$.

Bostick, B.C., Fendorf, S., 2003. Arsenite sorption on troilite $(\mathrm{FeS})$ and pyrite $\left(\mathrm{FeS}_{2}\right)$. Geochim. Cosmochim. Acta 67, 909-921.

Bostick, B.C., Chen, C., Fendorf, S., 2004. Arsenite retention mechanisms within estuarine sediments of Pescadero. CA. Environ. Sci. Technol. 38, 3299-3304.

Burton, E.D., Bush, R.T., Sullivan, L.A., Johnston, S.G., Hocking, R.K., 2008. Mobility of arsenic and selected metals during re-flooding of iron- and organic-rich acid-sulfate soil. Chem. Geol. 253, 64-73.

Burton, E.D., Johnston, S.G., Kocar, B.D., 2014. Arsenic mobility during flooding of contaminated soil: the effect of microbial sulfate reduction. Environ. Sci. Technol. 48, $13,660-13,667$.

Burton, E.D., Johnston, S.G., Planer-Friedrich, B., 2013. Coupling of arsenic mobility to sulfur transformations during microbial sulfate reduction in the presence and absence of humic acid. Chem. Geol. 343, 12-24.

Cheng, H.F., Hu, Y.A., Luo, J., Xu, B., Zhao, J.F., 2009. Geochemical processes controlling fate and transport of arsenic in acid mine drainage (AMD) and natural systems. J. Hazard. Mater. 165, 13-26.

Coker, V.S., Gault, A.G., Pearce, C.I., Van der Laan, G., Telling, N.D., Charnock, J.M., Polya, D.A., Lloyd, J.R., 2006. XAS and XMCD evidence for species-dependent partitioning of arsenic during microbial reduction of ferrihydrite to magnetite. Environ. Sci. Technol. 40, 7745-7750.

Cord-Ruwisch, R., 1985. A quick method for the determination of dissolved and precipitated sulfides in cultures of sulfate-reducing bacteria. J. Microbiol. Methods 4, 33-36.

Daus, B., Mattusch, J., Wennrich, R., Weiss, H., 2008. Analytical investigations of phenyl arsenicals in groundwater. Talanta 75, 376-379.

Deng, H.M., Evans, P.O.M., 1997. Social and environmental aspects of abandoned chemical weapons in china. Nonprol. Rev. 4, 101-108.

Fakih, M., Davranche, M., Dia, A., Nowack, B., Morin, G., Petitjean, P., Châtellier, X., Gruau, G., 2009. Environmental impact of $\mathrm{As}(\mathrm{V})$-Fe oxyhydroxide reductive dissolution: an experimental insight. Chem. Geol. 259, 290-303.

FAO-IUSS-ISRIC, 2014. World Soil Resources Reports No. 106 World Reference Base for Soil Resources. Food and Agriculture Organization of the United Nations (FAO), Rome.

Flynn, T.M., O'Loughlin, E.J., Mishra, B., DiChristina, T.J., Kemner, K.M., 2014. Sulfur-mediated electron shuttling during bacterial iron reduction. Nature 344, 1039-1042.

Guan, L., Hisatomi, S., Fujii, K., Nonaka, M., Harada, N., 2012. Enhanced transformation of diphenylarsinic acid in soil under sulfate-reducing conditions. J. Hazard. Mater. 241242, 355-362.

Haas, R., Schmidt, T.C., Steinbach, K., von Löw, E., 1998. Chromatographic determination of phenylarsenic compounds. Fresenius J. Anal. Chem. 361, 313-318.

Hanaoka, S., Nagasawa, E., Nomura, K., Yamazawa, M., Ishizaki, M., 2005. Determination of diphenylarsenic compounds related to abandoned chemical warfare agents in environmental samples. Appl. Organomet. Chem. 19, 265-275.

Hansel, C.M., Benner, S.G., Neiss, J., Dohnalkova, A., Kukkadapu, R.K., Fendorf, S., 2003. Secondary mineralization pathways induced by dissimilatory iron reduction of ferrihydrite under advective flow. Geochim. Cosmochim. Acta 67, 2977-2992.

Hempel, M., Daus, B., Vogt, C., Weiss, H., 2009. Natural attenuation potential of phenylarsenicals in anoxic groundwaters. Environ. Sci. Technol. 43, 6989-6995. 
Hisatomi, S., Guan, L., Nakajima, M., Fujii, K., Nonaka, M., Harada, N., 2013. Formation of diphenylthioarsinic acid from diphenylarsinic acid under anaerobic sulfate-reducing soil conditions. J. Hazard. Mater. 262, 25-30.

Huang, J.H., Voegelin, A., Pombo, S.A., Lazzaro, A., Zeyer, J., Kretzschmar, R., 2011. Influence of arsenate adsorption to ferrihydrite, goethite, and boehmite on the kinetics of arsenate reduction by Shewanella putrefaciens strain CN-32. Environ. Sci. Technol. 45, 7701-7709.

Hunter, R.C., Hitchcock, A.P., Dynes, J.J., Obst, M., Beveridge, T.J., 2008. Mapping the speciation of iron in Pseudomonas aeruginosa biofilms using scanning transmission X-ray microscopy. Environ. Sci. Technol. 42, 8766-8772.

Ishizaki, M., Yanaoka, T., Nakamura, M., Hakuta, T., Ueno, S., Komuro, M., Shibata, M., Kitamura, T., Honda, A., Doy, M., Ishii, K., Tamaoka, A., Shimojo, N., Ogata, T. Nagasawa, E., Hanaoka, S., 2005. Detection of bis(diphenylarsine)oxide, diphenylarsinic acid and phenylarsonic acid, compounds probably derived from chemical warfare agents, in drinking well water. J. Health Sci. 51, 130-137.

Kappler, A., Benz, M., Schink, B., Brune, A., 2004. Electron shuttling via humic acids in microbial iron(III) reduction in a freshwater sediment. FEMS Microbiol. Ecol. 47, 85-92.

Kocar, B.D., Borch, T., Fendorf, S., 2010. Arsenic repartitioning during biogenic sulfidization and transformation of ferrihydrite. Geochim. Cosmochim. Acta 74, 980-994.

Kroening, K.K., Solivio, M.J.V., García-López, M., Puga, A., Caruso, J.A., 2009. Cytotoxicity of arsenic-containing chemical warfare agent degradation products with metallomic approaches for metabolite analysis. Metallomics 1, 59-66.

Kurata, H., 1980. Lessons learned from the destruction of the chemical weapons of the Japanese Imperial Forces. Chemical Weapons: Destruction and Conversion, pp. 77-93.

Langner, H.W., Inskeep, W.P., 2000. Microbial reduction of arsenate in the presence of ferrihydrite. Environ. Sci. Technol. 34, 3131-3136.

Li, S.X., 2011. Mechanism of Arsenic and Diphenylarsinic Acid Adsorption on Soil and Phytoremediation by Petris vittata Ph.D thesis Nanjing: Institute of Soil Science, Chinese Academy of Sciences.

Lovley, D.R., Phillips, E.J.P., 1986. Organic matter mineralization with reduction of ferric iron in anaerobic sediments. Appl. Environ. Microbiol. 51, 683-689.

Lu, R.K., 2000. Methods of Soil and Agrochemical Analysis. China Agricultural Science and Technology Press, Beijing.

Maejima, Y., Arao, T., Baba, K., 2011. Transformation of diphenylarsinic acid in agricultural soils. J. Environ. Qual. 40, 76-82.

Masscheleyn, P.H., Delaune, R.D., Patrick, W.H., 1991. Effect of redox potential and pH on arsenic speciation and solubility in a contaminated soil. Environ. Sci. Technol. 25, 1414-1419.

Muehe, E.M., Scheer, L., Daus, B., Kappler, A., 2013. Fate of Arsenic during Microbial reduction of biogenic versus abiogenic As-Fe(III)-mineral coprecipitates. Environ. Sci. Technol. 47, 8297-8307.

Ochi, T., Suzuki, T., Isono, H., Kaise, T., 2004. In vitro cytotoxic and genotoxic effects of diphenylarsinic acid, a degradation product of chemical warfare agents. Toxicol. Appl. Pharmacol. 200, 64-72.

Ohtsuka, T., Yamaguchi, N., Makino, T., Sakurai, K., Kimura, K., Kudo, K., Homma, E., Dong D.T., Amachi, S., 2013. Arsenic dissolution from Japanese paddy soil by a dissimilatory arsenate-reducing bacterium Geobacter sp. OR-1. Environ. Sci. Technol. 47, 6263-6271.

Pearson, G.S., Magee, R.S., 2002. Critical evaluation of proven chemical weapon destruction technologies (IUPAC Technical Report). Pure Appl. Chem. 74, 187-316.

Pedersen, H.D., Postma, D., Jakobsen, R., 2006. Release of arsenic associated with the reduction and transformation of iron oxides. Geochim. Cosmochim. Acta 70, 4116-4129.
Polizzotto, M.L., Harvey, C.F., Li, G.C., Badruzzman, B., Ali, A, Newville, M., Sutton, S. Fendorf, S., 2006. Solid-phases and desorption processes of arsenic within Bangladesh sediments. Chem. Geol. 228, 97-111.

Poulton, S.W., Krom, M.D., Raiswell, R., 2004. A revised scheme for the reactivity of iron (oxyhydr)oxide minerals towards dissolved sulfide. Geochim. Cosmochim. Acta 68, 3703-3715.

Root, R.A., Fathordoobadi, S., Alday, F., Ela, W., Chorover, J., 2013. Microscale speciation of arsenic and iron in ferric-based sorbents subjected to simulated landfill conditions. Environ. Sci. Technol. 47, 12,992-13,000.

Schwertmann, U., Cornell, R.M., 2000. The Iron Oxides in the Laboratory: Preparation and Characterization. second ed. Wiley-VCH, Weinheim.

Shaheen, S.M., Rinklebe, J., Frohne, T., White, J.R., Delaune, R.D., 2015. Redox effects on release kinetics of arsenic, cadmium, cobalt, and vanadium in Wax Lake Deltaic freshwater marsh soils. Chemosphere 150, 740-748.

Sharma, P., Ofner, J., Kappler, A., 2010. Formation of binary and ternary colloids and dissolved complexes of organic matter, Fe and As. Environ. Sci. Technol. 44, 4479-4485.

Sharma, P., Rolle, M., Kocar, B., Fendorf, S., Kappler, A., 2011. Influence of natural organic matter on As transport and retention. Environ. Sci. Technol. 45, 546-553.

Stock, T., Lohs, K., 1997. The Challenge of Old Chemical Munitions and Toxic Armament Wastes. Oxford University Press, New York.

Stucker, V.K., Silverman, D.R., Williams, K.H., Sharp, J.O., Ranville, J.F., 2014. Thioarsenic species associated with increased arsenic release during biostimulated subsurface sulfate reduction. Environ. Sci. Technol. 48, 13,367-13,375.

Van Geen, A., Rose, J., Thoral, S., Garnier, J.M., Zheng, Y., Bottero, J.Y., 2004. Decoupling of As and Fe release to Bangladesh groundwater under reducing conditionsPart II: evidence from sediment incubations. Geochim. Cosmochim. Acta 68, 3475-3486.

Van Geen, A., Zheng, Y., Cheng, Z., Aziz, Z., Horneman, A., Dhar, R.K., Maolloux, B., Stute, M. Weinman, B., Goodbred, S., Seddique, A.A., Hoque, M.A., Ahmed, K.M., 2006. A transect of groundwater and desiment properties in Araihazar, Bangladesh: further evidence of decoupling between As and Fe mobilization. Chem. Geol. 228, 85-96.

Wallschläger, D., Stadey, C.J., 2007. Determination of (oxy) thioarsenates in sulfidic waters. Anal. Chem. 79, 3873-3880.

Wilkin, R.T., Ford, R.G., 2006. Arsenic solid-phase partitioning in reducing sediments of a contaminated wetland. Chem. Geol. 228, 156-174.

Xia, J.L., Liu, H.C., Nie, Z.Y., Peng, A.A., Zhen, X.J., Yang, Y., Zhang, X.L., 2013. Synchrotron radiation based STXM analysis and micro-XRF mapping of differential expression of extracellular thiol groups by Acidithiobacillus ferrooxidans grown on $\mathrm{Fe}^{2+}$ and $\mathrm{S}^{0}$. J. Microbiol. Methods 94, 257-261.

Xu, L.Y., Zhao, Z.X., Wang, S.F., Pan, R.R., Jia, Y.F., 2011. Transformation of arsenic in offshore sediment under the impact of anaerobic microbial activities. Water Res. 45 6781-6788.

Yamaguchi, N., Nakamura, T., Dong, D., Takahashi, Y., Amachi, S., Makino, T., 2011. Arsenic release from flooded paddy soils is influenced by speciation, $\mathrm{Eh}, \mathrm{pH}$, and iron dissolution. Chemosphere 83, 925-932.

Zhang, X.Z., Xu, Z.J., Tai, R.Z., Zhen, X.J., Wang, Y., Guo, Z., Yan, R., Chang, R., Wang, B., Li, M., Zhai, J., Gao, F., 2010. Ratio-contrast imaging of dual-energy absorption for element mapping with a scanning transmission X-ray microscope. J. Synchrotron Radiat. 17 804-809.

Zhu, M., Tu, C., Zhang, H.B., Luo, Y.M., Christie, P., 2016. Simultaneous determination of diphenylarsinic and phenylarsinic acid in amended soils by optimized solvent extraction coupled to HPLC-MS/MS. Geoderma 270, 109-116. 